\title{
Factors associated with vertebral fracture risk in patients with primary hyperparathyroidism
}

\author{
Cristina Eller-Vainicher ${ }^{1, *}$, Claudia Battista ${ }^{2, *}$, Vito Guarnieri', \\ Silvana Muscarella 2,3, Serena Palmieri ${ }^{1}$, Antonio Stefano Salcuni ${ }^{2}$, \\ Giuseppe Guglielmi" ${ }^{4}$, Sabrina Corbetta5, Salvatore Minisola6 ${ }^{6}$ Anna Spada ${ }^{1}$, \\ Geoffrey N Hendy ${ }^{7}$, David E C Cole ${ }^{\mathbf{8}}$, lacopo Chiodini ${ }^{\mathbf{1}}$ and Alfredo Scillitani ${ }^{2}$ \\ ${ }^{1}$ Unit of Endocrinology and Metabolic Diseases, Fondazione IRCCS Cà Granda-Ospedale Maggiore Policlinico, \\ Department of Clinical Sciences and Community Health, University of Milan, Padiglione Granelli, Via Francesco \\ Sforza 35, 20122 Milan, Italy, ²Unit of Endocrinology, 'Casa Sollievo della Sofferenza', IRCCS, San Giovanni Rotondo, \\ Foggia, Italy, ${ }^{3}$ Unit of Radiology, 'Fatebenefratelli and Oftalmico' Hospital, Milan, Italy, ${ }^{4}$ Unit of Radiology, \\ 'Casa Sollievo della Sofferenza', IRCCS, San Giovanni Rotondo, Foggia, Italy, ${ }^{5}$ Unit of Endocrinology and \\ Diabetology, Department of Biomedical Sciences for Health, IRCCS Policlinico San Donato, University of Milan, \\ San Donato Milanese, Milan, Italy, 'Department of Internal Medicine and Medical Disciplines, 'Sapienza' Rome \\ University, Rome, Italy, ${ }^{7}$ Departments of Medicine, Physiology, and Human Genetics, McGill University, \\ Montreal, Quebec, Canada and ${ }^{8}$ Departments of Laboratory Medicine and Pathobiology, Medicine and Genetics, \\ University of Toronto, Toronto, Ontario, Canada \\ * (C Eller-Vainicher and C Battista contributed equally to this work)
}

Correspondence should be addressed to I Chiodini Email

iacopo.chiodini@unimi.it

\begin{abstract}
Objective: To examine factors, in addition to bone mineral density (BMD), such as the common calcium-sensing receptor (CASR) gene polymorphisms, associated with vertebral fracture (VFx) risk in primary hyperparathyroidism (PHPT).

Design and methods: A cross-sectional analysis of 266 Caucasian PHPT seen as outpatients. Serum calcium (sCa) phosphate metabolism parameters were measured. BMD was assessed by dual-energy X-ray absorptiometry (expressed as Z-score) at lumbar spine (Z-LS) and femoral neck, morphometric VFx by radiograph, and CASR A986S/R990G genotypes by PCR amplification and genomic DNA sequencing.
\end{abstract}

Results: Fractured patients $(n=100,37.6 \%)$ had lower sCa $(10.8 \pm 0.7 \mathrm{mg} / \mathrm{dl})$ and Z-LS BMD $(-1.0 \pm 1.44)$, higher age (61 \pm 10 years), and prevalence (51\%) of $\geq 1 \mathrm{~S}$ alleles of the CASR A986S single-nucleotide polymorphism (SNP; AS/SS), than those not fractured $(n=166,11.2 \pm 1.0 \mathrm{mg} / \mathrm{dl},-0.57 \pm 0.97,58 \pm 13$ years, and $38 \%$ AS/SS, respectively, $P<0.05$ for all comparisons). Logistic regression, with VFx as dependent variable, showed independent risks associated with increased age (OR 1.03, 95\% Cl 1.01-1.06, $P=0.006$ ), decreased sCa (OR 1.86, 95\% Cl 1.28-2.7, $P=0.001$ ), and Z-LS BMD (OR 1.4, 95\% Cl $1.12-1.7, P=0.002)$ and presence of AS/SS (OR 1.8, 95\% Cl 1.1-2.9, $P=0.05)$. The presence of two out of three factors (age $\geq 58$ years, sCa $<10.8$ and Z-LS BMD $\leq-1.0$, and AS/SS genotype) gave an overall OR of $4.2(95 \% \mathrm{Cl} 2.25-7.85, P<0.0001)$. Conclusions: In PHPT, VFx is associated positively with age, negatively with sCa and spinal BMD, and presence of at least one copy of the CASR A986S SNP.

\section{Introduction}

Primary hyperparathyroidism (PHPT) is a frequent disease with a prevalence of $2-3 \%$ in postmenopausal women $(1,2)$. In PHPT patients, bone mineral density (BMD) is decreased and the risk of fractures increased $(3,4,5,6)$.
Although in PHPT the cortical bone is preferentially involved, an increased rate of vertebral fractures has been reported, which is partially independent of BMD $(7,8,9)$. Indeed, in PHPT patients, BMD does not reliably (c) 2014 European Society of Endocrinology Printed in Great Britain
Published by Bioscientifica Ltd. 
mirror the increased risk of fractures $(8,9)$, and a deterioration of bone quality (trabecular number, thickness, and connectivity) has been suggested to play a role $(10,11,12,13)$. To date, no studies have evaluated the additional possible risk factors for VFx besides BMD in PHPT (14).

The calcium-sensing receptor (CASR) is a G proteincoupled cell-surface glycoprotein expressed in parathyroid gland and renal tubular cells (15) and regulates the relationship between serum calcium ( $\mathrm{CCa}$ ) and parathyroid hormone (PTH) levels. The crucial role of CASR in blood calcium homeostasis is demonstrated by the fact that its inactivating and activating mutations cause familial hypocalciuric hypercalcemia and autosomal dominant hypocalcemia respectively (16). Three common single-nucleotide polymorphisms (SNPs) in exon 7 of the CASR gene (A986S, R990G, and Q1011E) have been described (17). The R990G polymorphism has been found to be associated with urinary calcium excretion in a population of Caucasian hypercalciuric stone formers (18) and in PHPT patients with renal stones $(19,20)$. The A986S variant has been found to be associated with sCa concentrations in normal Caucasian populations $(21,22,23)$, and to be more prevalent in PHPT, and associated with reduced risk of renal stones (23).

Although patients with CASR-inactivating mutations do not show a clear bone disease $(24,25)$, in the setting of PHPT, the CASR polymorphisms might be important for skeletal health. Indeed, elevated sCa levels seem to have CASR-mediated direct effects on osteoblasts, on the one hand, promoting their differentiation and activity, and on osteoclasts, on the other, inducing inhibition of osteoclastogenesis and bone resorption $(26,27)$.

The potential role of the CASR polymorphism in the determination of the fracture risk in PHPT patients has been incompletely investigated, particularly in relationship with other possible risk factors for fractures. Therefore, in this study, we evaluated the possible role of biochemical and clinical parameters together with the CASR A986S and R990G polymorphisms in identifying PHPT patients at increased risk for VFx.

\section{Patients and methods}

\section{Patients}

Among 335 Caucasian subjects with PHPT, referred by their general practitioners to our tertiary care outpatient Clinics for Metabolic Bone Diseases between January 2003 and December 2007, 266 patients (189 postmenopausal females, 40 premenopausal females, and 37 eugonadal males) were consecutively enrolled. The general practitioners in our area usually refer to our tertiary care outpatient Clinics for Metabolic Bone Diseases all patients with a convincing suspect of PHPT, regardless of a possible surgical indication.

PHPT was diagnosed by the presence of hypercalcemia and elevated or inappropriately normal PTH levels, after the exclusion of familial hypocalciuric hypercalcemia by the evaluation of the calcium clearance/creatinine clearance ratio (cutoff $<0.01 \mathrm{mg} / \mathrm{dl}$ ) in the presence of normal renal function (creatinine clearance estimated by Cockcroft-Gault equation $>60 \mathrm{ml} / \mathrm{min}$ ) (14). In patients with borderline sCa levels (i.e. between 10 and $10.4 \mathrm{mg} / \mathrm{dl}$, 2.5 and $2.6 \mathrm{mmol} / \mathrm{l}$ ), ionized calcium was assessed to confirm the diagnosis of PHPT. Only patients with ionized calcium levels higher than $1.33 \mathrm{mmol} / \mathrm{l}$ (normal values 1.13-1.32 mmol/l) were included in the study.

Sixty-nine patients were excluded on the basis of the following criteria: i) past or current history of hypogonadism, such as in males, testosterone levels $<3.0 \mathrm{ng} / \mathrm{ml}$ (one patient) and in females, menopause before 45 years (three patients) and of diseases known to affect bone metabolism, such as thyrotoxicosis (two patients), gastrointestinal disorders (three patients), chronic renal failure (three patients), chronic hepatic disease (three patients), depression (four patients), alcoholism (one patient), eating disorders (two patients), and rheumatological or hematological diseases (four and two patients respectively); ii) administration of drugs influencing bone metabolism or serum PTH and calcium levels, i.e. bisphosphonates (34 patients); and iii) history of a previous potentially high-energy VFx (nine patients). Patients with multiple endocrine neoplasia types 1 and 2-related PHPT were not included in the study (28).

All subjects gave their witnessed informed consent before entering the study, which was approved by Local Ethics Committees and in accordance with Helsinki Declaration II.

\section{Methods}

Serum and urine samples were collected and stored at $-80^{\circ} \mathrm{C}$ until assayed. In all subjects, the following was measured: sCa, phosphorus, creatinine, alkaline phosphatase total activity (ALP), intact PTH, 25-hydroxyvitamin D, and total testosterone (in males). Total calcium was corrected for serum albumin according to the formula: total calcium $+(4.0-$ albumin $(\mathrm{mg} / \mathrm{dl})) \times 0.8$ (reference interval: $8.4-10.4 \mathrm{~g} / \mathrm{dl}$ and 2.1-2.6 mmol/1) (29). Calcium 
and creatinine were measured in 24-h urine collections and calcium clearance/creatinine clearance ratio was calculated. sCa, phosphorus, albumin and creatinine, and urine calcium and creatinine were measured by standard colorimetric techniques. Serum intact PTH was measured by a chemiluminescent method (Nichols Institute Diagnostic, San Juan Capistrano, CA, USA) with intraassay coefficient of variation (CV) and interassay CV being 5.1 and $8.2 \%$ respectively. Serum 25-hydroxyvitamin $\mathrm{D}$ concentration was measured by chemiluminescent immunoassay (reference interval: $30-100 \mathrm{ng} / \mathrm{ml}$ and $75-250 \mathrm{nmol} / \mathrm{l})$. Serum ALP was measured by standard colorimetric techniques (reference interval: female, 35-104 U/1 and male, 40-129 U/1).

In all patients, BMD was measured by dual-energy X-ray absorptiometry (Hologic Discovery, Software version 13.3:3, Bedford, MA, USA) and expressed as $T$-score or Z-score, at lumbar (L1-L4) spine (T-LS or Z-LS, respectively, in vivo precision of $1.0 \%$ ), femoral neck (T-FN or Z-FN, respectively, in vivo precision of $1.8 \%$ ), and total femur (T-FT or Z-FT, respectively, in vivo precision of $1.7 \%$ ).

A conventional spinal radiograph in lateral and anteroposterior projection (T4-L4) was obtained in all subjects. Two physicians, blinded to the BMD and biochemical data, independently reviewed the radiographs; any questionable cases were discussed to reach an agreed diagnosis. VFxs were diagnosed on visual inspection using the semi-quantitative visual assessment (SQ) described by Genant et al. (30). All patients were screened for renal stones by abdominal ultrasound.

Genomic DNA was extracted from peripheral white blood cells using standard techniques. A 282-bp fragment of CASR exon 7 was amplified as described (21), and the CASR A986S and R990G genotypes were determined by direct sequencing. Patients heterozygous or homozygous for the $986 \mathrm{~S}$ allele (AS +SS group) and heterozygous or homozygous for the $990 \mathrm{G}$ allele (RG + GG group) were considered together due to the low frequency of the homozygous variants.

\section{Statistical analysis}

Statistical analysis was performed by SPSS version 18.0 Statistical Package (SPSS, Inc.). The results are expressed as mean \pm s.D., unless specified. The categorical variables were compared by $\chi^{2}$-test. Comparison of continuous variables among the different groups was made using Student's $t$-test or Mann-Whitney $U$-test, as appropriate. A general linear modeling was used to compare the variables found to be different between patients with and without VFx, after adjusting for age. Bivariate associations between the biochemical parameters were tested by either Pearson's product moment correlation or Spearman's correlation, as appropriate. The logistic regression analysis assessed the independent association between VFx and the variables that were significantly different between patients with and without VFx.

The receiver operating characteristic (ROC) curve analysis was performed to assess the cutoff values for the variables found to be independently associated with the presence of VFx. On the basis of the obtained cutoffs, the diagnostic accuracy (sensitivity (SN), specificity (SP), and overall accuracy) of these variables (taken singularly and in combination) for detecting VFx was assessed. Finally, the logistic regression analysis was again used to test association between the presence of VFx and the combination of variables with the best diagnostic accuracy for predicting VFx after adjusting for possible confounding factors. $P$ values of $<0.05$ were considered statistically significant.

\section{Results}

The VFx prevalence in this Italian PHPT population was $37.6 \%$. The biochemical and clinical characteristics of all patients and of those with $(\mathrm{VFx}+)$ and without VFx $(\mathrm{VFx}-)$ are given in Table 1 . Compared with VFxpatients, VFx + patients were older and had lower calcium T-LS, Z-LS, T-FN, and T-FT BMD levels and higher prevalence of the CASR $986 \mathrm{~S}$ alleles, while all other parameters were comparable. In particular, the prevalence of CASR R990G was not different between patients with and without VFx. Two patients showed inappropriately normal PTH levels (41 pg/dl). In both cases, calcium levels were above $11.5 \mathrm{mg} / \mathrm{dl}$, with calcium clearance/creatinine clearance ratio $>0.02$ and 24 -h urinary calcium $>250 \mathrm{mg} /$ day.

The number of VFx was not associated with any biochemical parameter. In VFx + patients, the proportions of postmenopausal females (40.2\%) and of males (43.2\%) was higher than that of premenopausal females $(20 \%$, $P=0.05$ for both comparisons). Apart from the prevalence of VFx, the biochemical and clinical characteristics of the AS/SS group were comparable to those of the AA group (Table 2).

Logistic regression analysis showed that increasing age, Z-LS BMD, and the presence of at least one $986 \mathrm{~S}$ allele were independently associated with the presence of VFx, while female gender and BMI were not. sCa levels were inversely associated with VFx (Table 3). 


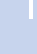

Table 1 Clinical and biochemical characteristics of all patients and of patients with (VFx + ) and without (VFx - ) vertebral fractures. Data are mean \pm s.D. with range in parentheses for the whole sample (All) or absolute number with percentage in parentheses. BMI, calcium, PTH, phosphorous, creatinine, ALP, urinary calcium, and 25-hydroxyvitamin D levels between VFx - and VFx + groups were compared by general linear modeling after adjusting for age and expressed as mean \pm s.E.M. with range in parentheses.

\begin{tabular}{|c|c|c|c|c|}
\hline & All $(n=266)$ & $\mathbf{V F x}-(n=166)$ & $\mathbf{V F x}+(n=100)$ & $\begin{array}{c}\text { P level } \\
\text { (vs VFx }- \text { ) }\end{array}$ \\
\hline Age (years) & $59.1 \pm 12.2$ (19 to 90$)$ & $57.9 \pm 13.1$ (19 to 90$)$ & $61.1 \pm 10.1$ (31 to 82$)$ & 0.034 \\
\hline Females (\%) & $229(86.1)$ & $145(87.3)$ & $84(84)$ & 0.445 \\
\hline BMI $\left(\mathrm{kg} / \mathrm{m}^{2}\right)$ & $27.2 \pm 5.5(15$ to 51$)$ & $27.7 \pm 0.42$ ( 15 to 51$)$ & $26.6 \pm 0.55$ (17.9 to 44$)$ & 0.121 \\
\hline Calcium (mg/dl) & $11.1 \pm 0.9(10$ to 17.2$)$ & $11.2 \pm 0.07$ (10 to 17.2$)$ & $10.8 \pm 0.09$ (10 to 12.6$)$ & 0.001 \\
\hline PTH $(p g / m l)$ & $169.1 \pm 130.7$ (41 to 973$)$ & $175.1 \pm 10.2$ (41 to 973$)$ & $159.5 \pm 13.2$ (41 to 697$)$ & 0.345 \\
\hline Phosphorous (mg/dl) & $2.7 \pm 0.05$ (1.1 to 4$)$ & $2.6 \pm 0.5(1.4$ to 4$)$ & $2.8 \pm 0.06$ (1.1 to 4$)$ & 0.113 \\
\hline Creatinine (mg/dl) & $0.88 \pm 0.19(0.4$ to 1.5$)$ & $0.9 \pm 0.02(0.5$ to 1.4$)$ & $0.9 \pm 0.03(0.4$ to 1.5$)$ & 0.844 \\
\hline $\operatorname{ALP}(U / I)$ & $101.8 \pm 54.4$ (42 to 462$)$ & $100.3 \pm 4.6(42$ to 350$)$ & $96.2 \pm 5.8(42$ to 462$)$ & 0.589 \\
\hline Urinary calcium (mg/24 h) & $326.9 \pm 158.4(103$ to 914$)$ & $334.7 \pm 11(103$ to 914$)$ & $316.9 \pm 13.5$ (104 to 577$)$ & 0.308 \\
\hline 25-Hydroxyvitamin D (ng/ml) & $17.1 \pm 12(2.7$ to 72$)$ & $16.3 \pm 1.2(2.1$ to 66$)$ & $18.5 \pm 1.5$ (2.1 to 72$)$ & 0.243 \\
\hline Prevalence of renal stones (\%) & $136(51.5)$ & $87(52.7)$ & $49(49.5)$ & 0.611 \\
\hline T-LS (T-score) & $-1.76 \pm 1.37(-5.5$ to 2.7$)$ & $-1.57 \pm 1.33(-5.0$ to 2.0$)$ & $-2.07 \pm 1.39(-5.5$ to 2.7$)$ & 0.004 \\
\hline Z-LS (Z-score) & $-0.75 \pm 1.35(-3.6$ to 2.5$)$ & $-0.57 \pm 0.97(-5.0$ to 3.8$)$ & $-1.0 \pm 1.44(-5.0$ to 3.8$)$ & 0.006 \\
\hline T-FN (T-score) & $-1.20 \pm 1.09(-5.0$ to 3.3$)$ & $-1.09 \pm 1.07(-3.5$ to 3.3$)$ & $-1.37 \pm 1.1(-5.0$ to 3.1$)$ & 0.043 \\
\hline Z-FN (Z-score) & $-0.59 \pm 1.08(-3.0$ to 3.2$)$ & $-0.53 \pm 0.97(-5.0$ to 5.3$)$ & $-0.70 \pm 1.23(-5.0$ to 5.3$)$ & 0.198 \\
\hline T-FT (T-score) & $-1.06 \pm 1.01(-4.2$ to 2.4$)$ & $-0.97 \pm 1.04(-3.0$ to 2.4$)$ & $-1.23 \pm 0.95(-4.2$ to 1.3$)$ & 0.04 \\
\hline Z-FT (Z-score) & $-0.57 \pm 0.99(-3.8$ to 2.7$)$ & $-0.48 \pm 0.98(-2.5$ to 2.5$)$ & $-0.71 \pm 0.98(-3.8$ to 2.7$)$ & 0.081 \\
\hline Prevalence of osteoporosis ${ }^{\mathrm{a}}(\%)$ & $100(37.6)$ & $76(45.8)$ & $100(100)$ & 0.0001 \\
\hline Number of VFx & $2.6 \pm 2.9(1$ to 21$)$ & - & $2.6 \pm 2.9(1$ to 21$)$ & - \\
\hline $\begin{array}{l}\text { AS + SS genotypes of CASR } \\
\text { A986S polymorphism (\%) }\end{array}$ & $114(42.9)$ & $63(38)$ & $51(51)$ & 0.037 \\
\hline $\begin{array}{l}\text { RG + GG genotypes of CASR } \\
\text { R990G polymorphism (\%) }\end{array}$ & $22(8.3)$ & $13(7.8)$ & $9(9)$ & 0.737 \\
\hline
\end{tabular}

ALP, alkaline phosphatase total activity; T-LS or Z-LS, T-FN or Z-FN, and T-FT or Z-FT: bone mineral density measured by dual X-ray energy absorptiometry and expressed as T-score or Z-score at spine (L1-L4), femoral neck, and total femur respectively. VFx: vertebral fractures. SI conversion factors: calcium, 0.25; PTH, 1.0; phosphorous, 0.32 ; creatinine, 88.4; and 25-hydroxyvitamin D, 2.5.

aprevalence of osteoporosis: $T$-score at any site $<-2.5$ and/or presence of VFx.

The ROC analysis, performed to assess the best threshold values of age, calcium, and Z-LS BMD, for predicting VFx, showed that age, calcium, and Z-LS BMD, taken singly, have a poor accuracy for predicting VFx (area under the curve: $0.57,0.62$, and 0.58 , respectively; $P=0.05$, $P=0.001$, and $P=0.028$ respectively). The cutoffs with the best compromise between $\mathrm{SN}$ and SP were set at 58 years of age, $10.8 \mathrm{mg} / \mathrm{dl}$ (2.7 mmol/l) for sCa and - 1.0 for Z-LS BMD.

The SN, SP, and overall accuracy for predicting VFx of age $\geq 58$ years, calcium $<10.8 \mathrm{mg} / \mathrm{dl}(2.7 \mathrm{mmol} / \mathrm{l})$, and Z-LS BMD levels $\leq-1.0$ and of the presence of $\geq 1$ (criterion 1 ), $\geq 2$ (criterion 2 ), or all 3 of these factors (criterion 3 ) are given in Table 4. The presence of at least one factor or the simultaneous presence of these three factors (criterion 1 and criterion 3 respectively) showed the best SN (92\%, eight false negatives out of the $100 \mathrm{VFx}+$ patients) and SP (92.8\%, 12 false positives out of $166 \mathrm{VFx}$ - patients), respectively, for detecting PHPT patients with VFx.

Among patients with 0,1 , or $\geq 2$ factors among age $\geq 58$ years, calcium $<10.8 \mathrm{mg} / \mathrm{dl}(2.7 \mathrm{mmol} / \mathrm{l})$ and Z-LS
BMD levels $\leq-1.0$, the prevalence of patients with VFx was 7,31 , and $62 \%$, respectively, as shown in Fig. 1. The presence of $\geq 2$ factors and the AS/SS genotypes was associated with the presence of VFx (OR 4.2, 95\% CI 2.25-7.85, $P<0.0001$ ), regardless of BMI (OR 1.02, 95\% CI $0.97-1.08, P=0.349$ ) and female gender (OR 1.88, 95\% CI 0.91-3.84, $P=0.1$ ).

Given the small number of male patients and the possible influence of gender on BMD, we repeated the analyses after excluding male patients and the results were substantially confirmed (data not shown).

\section{Discussion}

The study is the first to investigate a set of disease-related clinical, biochemical, and genetic factors associated with VFx in a large cohort of PHPT patients. The VFx prevalence in this study (38\%) is in keeping with those reported in previous studies $(9,11,12)$. Our data show that these VFx are associated directly with age and inversely with spinal 
Table 2 Comparison of the clinical and biochemical characteristics between patients with AA and patients with AS + SS of the CASR A986S polymorphism. Data are mean \pm S.D. with range or absolute number with percentage in parentheses.

\begin{tabular}{l}
\hline \\
\hline Age (years) \\
Females $(\%)$ \\
BMI $\left(\mathrm{kg} / \mathrm{m}^{2}\right)$ \\
Calcium $(\mathrm{mg} / \mathrm{dl})$ \\
PTH $(\mathrm{pg} / \mathrm{ml})$ \\
Phosphorous $(\mathrm{mg} / \mathrm{dl})$ \\
Creatinine $(\mathrm{mg} / \mathrm{dl})$ \\
ALP $(U / \mathrm{l})$ \\
Urinary calcium (mg/24 h) \\
25-Hydroxyvitamin D (ng/ml) \\
Prevalence of renal stones (\%) \\
T-LS (T-score) \\
Z-LS (Z-score) \\
T-FN ( $T$-score) \\
Z-FN (Z-score) \\
T-FT ( $T$-score) \\
Z-FT (Z-score) \\
Prevalence of osteoporosis ${ }^{\text {a }}(\%)$ \\
Number of VFx \\
Prevalence of VFx (\%)
\end{tabular}

\begin{tabular}{c}
\hline AA group ( $n=152)$ \\
$59.1 \pm 11.7(19$ to 90$)$ \\
$129(84.9)$ \\
$27 \pm 5(15$ to 51$)$ \\
$11.2 \pm 1.0(10$ to 17.2$)$ \\
$173.2 \pm 138.9(41$ to 973$)$ \\
$2.7 \pm 0.5(1.4$ to 4$)$ \\
$0.88 \pm 0.2$ (0.4 to 1.5$)$ \\
$101.4 \pm 50.7(40$ to 462$)$ \\
$335.3 \pm 146.4(103$ to 914$)$ \\
$18.3 \pm 13.2(2.7$ to 72$)$ \\
$84(55.3)$ \\
$-1.75 \pm 1.38(-5.0$ to 2.7$)$ \\
$-0.76 \pm 1.37(-5.0$ to 3.8$)$ \\
$-1.19 \pm 1.09(-5.0$ to 3.3$)$ \\
$-0.61 \pm 1.03(-5.0$ to 3.2$)$ \\
$-1.04 \pm 1.03(-4.2$ to 2.1$)$ \\
$-0.58 \pm 0.97(-3.8$ to 2.5$)$ \\
$94(61.8)$ \\
$2.7 \pm 3.2(1$ to 21$)$ \\
49 (32.2)
\end{tabular}

\begin{tabular}{|c|}
\hline AS + SS group $(n=114)$ \\
\hline 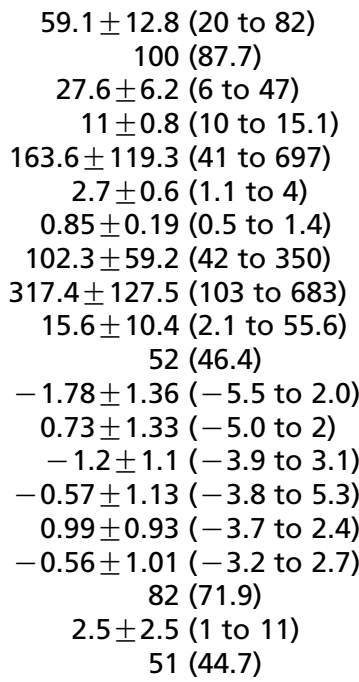 \\
\hline
\end{tabular}

\begin{tabular}{l}
\hline P level \\
\hline 0.976 \\
0.506 \\
0.432 \\
0.082 \\
0.406 \\
0.423 \\
0.128 \\
0.901 \\
0.312 \\
0.142 \\
0.156 \\
0.844 \\
0.896 \\
0.949 \\
0.772 \\
0.723 \\
0.914 \\
0.085 \\
0.725 \\
0.037
\end{tabular}

ALP, alkaline phosphatase total activity; T-LS or Z-LS, T-FN or Z-FN, and T-FT or Z-FT: bone mineral density measured by dual X-ray energy absorptiometry and expressed as T-score or Z-score at spine (L1-L4), femoral neck, and total femur respectively. VFx: vertebral fractures. SI conversion factors: calcium, 0.25 ; PTH, 1.0; phosphorous, 0.32; creatinine 88.4; and 25-hydroxyvitamin D, 2.5.

aPrevalence of osteoporosis: $T$-score at any site $<-2.5$ and/or presence of VFx.

BMD and sCa levels. In addition, the CASR 9865 genotype is more frequent in patients with VFx.

In our VFx-positive patients, femoral BMD tended to be lower than in VFx-negative patients, but the difference did not reach statistical significance. In contrast, the finding that sCa levels were lower in VFx-positive patients is novel and unexpected. A possible explanation is that PHPT patients with mildly elevated sCa levels (i.e. $<10.8 \mathrm{mg} / \mathrm{dl}$ and $2.7 \mathrm{mmol} / \mathrm{l}$ ) may have been definitively diagnosed as such only after several years of observation, so that the disease duration has, in fact, been longer than in those patients with more clear-cut elevations of sCa levels, which would have been diagnosed earlier. In keeping with this notion, data from another cohort of PHPT patient revealed an increased fracture risk as early as 10 years before the diagnosis of PHPT had been made (6). This may be due to the fact that the diagnosis of secondary osteoporosis can be challenging and, in particular, the diagnosis of PHPT may be concealed by other factors, such as concomitant hypovitaminosis D (31). The patients included in this study had been referred to our tertiary care centers by general practitioners, and the diagnosis of PHPT may depend on the individual clinical picture. Moreover, a further possible explanation for the finding of lower calcium levels in PHPT patients with VFxs is that the occurrence of a VFx might have led to a diagnostic work-up that otherwise would not have been performed. It is possible, indeed, that the diagnosis of PHPT may have been done thanks to the biochemical examinations following the radiological evidence of a VFx.

The findings of this study may be of clinical relevance. Indeed, the combination of factors (age $\geq 58$ years, calcium $<10.8 \mathrm{mg} / \mathrm{dl}$ and $2.7 \mathrm{mmol} / \mathrm{l}$, spinal BMD $Z$-score $\leq-1.0$ ) may be useful for deciding who should be more aggressively screened for VFx. In the absence of any of these factors, the likelihood of being VFx-positive is

Table 3 Factors independently associated with vertebral fractures assessed by logistic regression analysis. Z-LS: bone mineral density measured by dual energy X-ray absorptiometry and expressed as Z-score at spine (L1-L4). AS+SS: presence of the AS or SS genotypes of the CASR A986S polymorphism.

\begin{tabular}{|c|c|c|c|}
\hline & OR & $95 \% \mathrm{Cl}$ & $\boldsymbol{P}$ \\
\hline Age (1 year increase) & 1.03 & $1.01-1.06$ & 0.006 \\
\hline Gender (male) & 1.9 & $0.83-4.1$ & 0.1 \\
\hline BMI (1 kg/m² increase) & 1.01 & $0.96-1.1$ & 0.545 \\
\hline $\begin{array}{l}\text { Calcium (1 mg/dl and } \\
0.25 \mathrm{mmol} / \mathrm{l} \text { decrease) }\end{array}$ & 1.86 & $1.28-2.7$ & 0.001 \\
\hline Z-LS (1 s.D. decrease) & 1.4 & $1.12-1.7$ & 0.002 \\
\hline $\begin{array}{l}\text { AS + SS genotypes } \\
\text { (presence) }\end{array}$ & 1.8 & $1.1-2.9$ & 0.05 \\
\hline
\end{tabular}


Table 4 Sensitivity (SN), specificity (SP), and overall accuracy (ACC) for predicting VFx of age, calcium, and Z-LS BMD taken singularly and in combination in PHPT patients. Z-LS: bone mineral density measured by dual energy X-ray absorptiometry and expressed as Z-score at spine (L1-L4). Criterion 1, Criterion 2 , and Criterion 3 are defined by the presence of at least one (criterion 1), at least two (criterion 2), or all three factors (criterion 3 ) among high age (i.e. $\geq 58$ years), low calcium (i.e. $<10.8 \mathrm{mg} / \mathrm{dl}$ and $2.7 \mathrm{mmol} / \mathrm{l}$ ), and low Z-LS BMD (i.e. $\leq-1.0$ ).

\begin{tabular}{|c|c|c|c|}
\hline & SN & SP & ACC \\
\hline Age $\geq 58$ years & 68 & 47 & 54.9 \\
\hline $\begin{array}{l}\text { Calcium }<10.8 \mathrm{mg} / \mathrm{dl} \\
\text { and } 2.7 \mathrm{mmol} / \mathrm{l}\end{array}$ & 57 & 63.3 & 60.0 \\
\hline Z-LS $\leq-1.0$ & 48 & 59.6 & 55.2 \\
\hline Criterion 1 & 92 & 13.9 & 43.2 \\
\hline Criterion 2 & 62 & 63.3 & 62.7 \\
\hline Criterion 3 & 18 & 92.8 & 64.7 \\
\hline
\end{tabular}

low (SN, 92\%), while in the presence of all these factors the likelihood is high (SP, 93\%).

Another finding of interest is the association of CASR 986S genotype with VFx regardless of age, gender, BMD, or sCa. In patients with the AS/SS genotypes plus at least two out of the three above-mentioned factors (age, sCa, and spinal BMD) the risk of VFx is increased 4.7-fold. Whether this may be a useful clinical tool for identifying PHPT patients at risk for fracture deserves further study.

Association with the CASR A986S SNP is novel with its potential for modulating the bone disease in PHPT. Indeed, elevated sCa levels have been suggested to have CASR-mediated direct effects on osteoblasts, promoting their differentiation and activity, and on osteoclasts inducing inhibition of osteoclastogenesis and of bone resorption $(26,27)$. In PHPT, bone apposition and resorption are both increased, but uncoupled, with a net negative calcium balance (8). In this setting, the reduction of the $\mathrm{SN}$ to calcium levels may increase this uncoupling. Indeed, it is possible that in PHPT patients with the AS/SS genotypes, the reduced SN to extracellular calcium levels results in a sub-clinical impairment of osteoblast function and enhances osteoclastic activity, resulting in a further increase in uncoupling of bone apposition and resorption (32). This could lead to a reduction in bone quality $(11,12)$, and thereby explain the increased VFx prevalence, independent of BMD, in AS/SS-genotype PHPT subjects.

These findings should be interpreted with caution. First, the cross-sectional design of the study cannot reveal causality but only association between variables. In addition, the sample size, though relatively large, did not allow us to develop the algorithm for detecting patients at risk for fracture on one half of the data sample and to test it on the other half. Second, the difference in the prevalence of the CASR AS or SS genotypes found between fractured (51\%) and non-fractured (38\%) patients was at the limit of statistical significance $(P=0.05)$. Third, patients with $C A S R$ inactivating mutations (i.e. familial hypocalciuric hypercalcemia) are not at any higher risk of overt bone loss $(24,25)$. Finally, a genome-wide association study, aimed at identifying new candidate genes for osteoporosis, did not uncover a significant association between bone strength phenotype and CASR (33). On the other hand, the differences between this study and others could be explained, at least in part, by considering that in our study, patients with frankly elevated serum PTH levels were included, representing a very different population as compared with other groups. Unfortunately, for budget restrictions we could only assess the A986S and R990G SNPs and not Q1011E Q1011E or the rs7652589 and rs1501899 SNPs sited in the noncoding regulatory region of the of the CASR gene. This is a possible limit of the study. Indeed, even if previous studies suggested that the A986S and R990G in particular are potentially involved in the pathogenesis of bone alteration in PHPT, it is not possible to exclude that the assessment of the Q1011E or the rs7652589 and rs1501899 SNPs could have given additional information $(19,20)$.

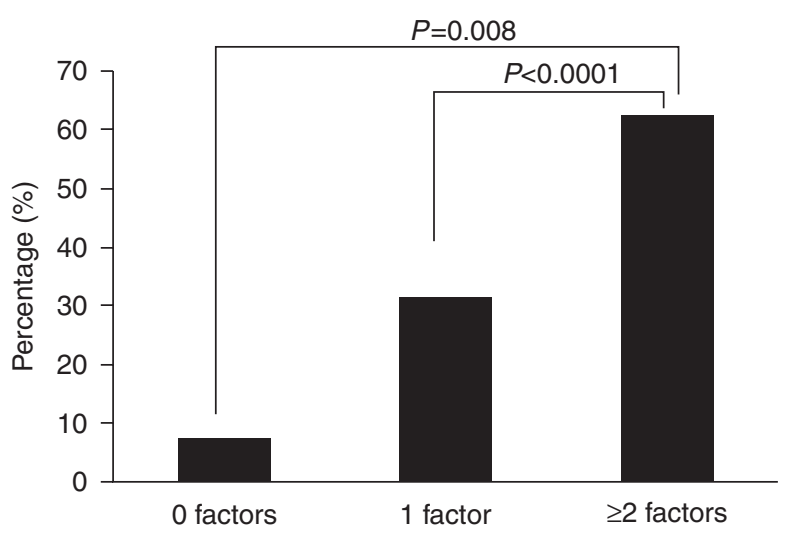

\section{Figure 1}

Differences in the prevalence of vertebral fractures in patients with 0,1 , or $\geq 2$ factors among age $\geq 58$ years, calcium $<10.8 \mathrm{mg} / \mathrm{dl}(2.7 \mathrm{mmol} / \mathrm{l})$, and Z-LS BMD levels $\leq-1.0$. Age, calcium levels, and Z-LS BMD were the sole parameters significantly associated with the presence of vertebral fractures by logistic regression analysis. The cutoffs used for age, calcium levels, and Z-LS BMD were assessed by receiver operating characteristic (ROC) curve analysis. 
In summary, this study shows that in PHPT patients: i) the presence of VFx is associated directly with age and inversely with sCa levels and spinal BMD and with the presence of the CASR $986 \mathrm{~S}$ genotype; ii) the simultaneous presence of the factors, age, sCa level, and Z-score BMD at the spine is associated with greater likelihood of VFx; and iii) in patients with the CASR $986 \mathrm{~S}$ genotype plus at least two out of the three above-mentioned factors, the possibility of a VFx is increased by more than fourfold.

\section{Declaration of interest}

The authors declare that there is no conflict of interest that could be perceived as prejudicing the impartiality of the research reported.

\section{Funding}

This research did not receive any specific grant from any funding agency in the public, commercial or not-for-profit sector.

\section{Acknowledgements}

The authors thank all patients for their participation. I Chiodini takes responsibility for the integrity of the data analysis.

\section{References}

1 Melton LJ III. Epidemiology of primary hyperparathyroidism. Journal of Bone and Mineral Research 19956 25-30. (doi:10.1002/jbmr. 5650061409)

2 Lundgren E, Rastad J, Thurfjell E, Akerstrom G \& Ljunghall S. Population-based screening for primary hyperparathyroidism with serum calcium and parathyroid hormone values in menopausal women. Surgery 1997121 287-294. (doi:10.1016/S00396060(97)90357-3)

3 Mosekilde L. Primary hyperparathyroidism and the skeleton. Clinical Endocrinology 200869 1-19. (doi:10.1111/j.1365-2265.2007.03162.x)

4 Larsson K, Ljunghall S, Krusemo UB, Naessen T, Lindh E \& Persson I. The risk of hip fractures in patients with primary hyperparathyroidism: a population-based cohort study with a follow-up of 19 years. Journal of Internal Medicine 1993234 585-593. (doi:10.1111/j.1365-2796.1993. tb01017.x

5 Khosla S, Melton LJ III, Wermers RA, Crowson CS, O’Fallon WM \& Riggs BL. Primary hyperparathyroidism and the risk of fracture: a population-based study. Journal of Bone and Mineral Research 199414 1700-1707. (doi:10.1359/jbmr.1999.14.10.1700)

6 Vestergaard P, Mollerup CL, Frøkjaer VG, Christiansen P, BlichertToft M \& Mosekilde L. Cohort study of risk of fracture before and after surgery for primary hyperparathyroidism. BMJ 2000321 598-602. (doi:10.1136/bmj.321.7261.598)

7 Dempster DW, Parisien M, Silverberg SJ, Liang XG, Schnitzer M, Shen V, Shane E, Kimmel DB, Recker R, Lindsay R et al. On the mechanism of cancellous bone preservation in postmenopausal women with mild primary hyperparathyroidism. Journal of Clinical Endocrinology and Metabolism 1999840 1562-1566. (doi:1210/jcem.84.5.5652)

8 De Geronimo S, Romagnoli E, Diacinti D, D'Erasmo E \& Minisola S. The risk of fractures in postmenopausal women with primary hyperparathyroidism. European Journal of Endocrinology $2006 \mathbf{1 5 5}$ 415-420. (doi:10.1530/eje.1.02225)

9 Vignali E, Viccica G, Diacinti D, Cetani F, Cianferotti L, Ambrogini E, Banti C, Del Fiacco R, Bilezikian JP, Pinchera A et al. Morphometric vertebral fractures in postmenopausal women with primary hyperparathyroidism. Journal of Clinical Endocrinology and Metabolism 200994 2306-2312. (doi:10.1210/jc.2008-2006)

10 Bilezikian JP. Bone strength in primary hyperparathyroidism. Osteoporosis International 200314 S113-S115. (doi:10.1007/s00198-003-1482-4)

11 Eller-Vainicher C, Filopanti M, Palmieri S, Ulivieri FM, Morelli V, Zhukouskaya VV, Cairoli E, Pino R, Naccarato A, Verga U et al. Bone quality, as measured by trabecular bone score, in patients with primary hyperparathyroidism. European Journal of Endocrinology 2013169 155-162. (doi:10.1530/EJE-13-0305)

12 Romagnoli E, Cipriani C, Nofroni I, Castro C, Angelozzi M, Scarpiello A, Pepe J, Diacinti D, Piemonte S, Carnevale V et al. "Trabecular bone score" (TBS): an indirect measure of bone micro-architecture in postmenopausal patients with primary hyperparathyroidism. Bone 201253 154-159. (doi:10.1016/j.bone.2012.11.041)

13 Silva BC, Boutroy S, Zhang C, McMahon DJ, Zhou B, Wang J, Udesky J, Cremers S, Sarquis M, Guo XD et al. Trabecular bone score (TBS) - a novel method to evaluate bone microarchitectural texture in patients with primary hyperparathyroidism. Journal of Clinical Endocrinology and Metabolism 201398 1963-1970. (doi:10.1210/jc.2012-4255)

14 Eastell R, Arnold A, Brandi ML, Brown EM, D'Amour P, Hanley DA, Rao DS, Rubin MR, Goltzman D, Silverberg SJ et al. Diagnosis of asymptomatic primary hyperparathyroidism: Proceedings of the Third International Workshop. Journal of Clinical Endocrinology and Metabolism 200994 340-350. (doi:10.1210/jc.2008-1758)

15 Brown EM, Pollak M \& Hebert SC. The extracellular calcium-sensing receptor: its role in health and disease. Annual Review of Medicine 1998 49 15-29. (doi:10.1146/annurev.med.49.1.15)

16 Hendy GN, D’Souza-Li L, Yang B, Canaff L \& Cole DEC. Mutations of the calcium-sensing receptor (CASR) in familial hypocalciuric hypercalcemia, neonatal severe hyperparathyroidism, and autosomal dominant hypocalcemia. Human Mutation 200016 281-296. (doi:10.1002/ 1098-1004(200010)16:4 < 281::AID-HUMU1 > 3.0.CO;2-A)

17 Heath H III, Odelberg S, Jackson CE, Teh BT, Hayward N, Larsson C, Buist NR, Krapcho KJ, Hung BC, Capuano IV et al. Clustered inactivating mutations and benign polymorphisms of the calcium receptor gene in familial benign hypocalciuric hypercalcemia suggest receptor functional domains. Journal of Clinical Endocrinology and Metabolism 199681 1312-1317. (doi:10.1210/jcem.81.4.8636323)

18 Scillitani A, Guarnieri V, Battista C, De Geronimo S, Muscarella LA, Chiodini I, Cignarelli M, Minisola S, Bertoldo F, Francucci CM et al. Primary hyperparathyroidism and the presence of kidney stones are associated with different haplotypes of the calcium-sensing receptor. Journal of Clinical Endocrinology and Metabolism 200792 277-283. (doi:10.1210/jc.2006-0857)

19 Vezzoli G, Tanini A, Ferrucci L, Soldati L, Bianchin C, Franceschelli F, Malentacchi C, Porfirio B, Adamo D, Terranegra A et al. Influence of calcium-sensing receptor gene on urinary calcium excretion in stoneforming patients. Journal of the American Society of Nephrology 200213 2517-2523. (doi:10.1097/01.ASN.0000030077.72157.D2)

20 Corbetta S, Eller-Vainicher C, Filopanti M, Saeli P, Vezzoli G, Arcidiacono T, Loli P, Syren ML, Soldati L, Beck-Peccoz P et al. R990G polymorphism of the calcium-sensing receptor and renal calcium excretion in patients with primary hyperparathyroidism. European Journal of Endocrinology 2006155 687-692. (doi:10.1530/eje.1.02286)

21 Cole DE, Peltekova VD, Rubin LA, Hawker GA, Vieth R, Liew CC, Hwang DM, Evrovski J \& Hendy GN. A986S polymorphism of the calcium-sensing receptor and circulating calcium concentrations. Lancet 1999353 112-115. (doi:10.1016/S0140-6736(98)06434-4)

22 Cole DE, Vieth R, Trang HM, Wong BY, Hendy GN \& Rubin LA. Association between total serum calcium and the A986S polymorphism 
of the calcium-sensing receptor gene. Molecular Genetics and Metabolism 200172 168-174. (doi:10.1006/mgme.2000.3126)

23 Scillitani A, Guarnieri V, De Geronimo S, Muscarella LA, Battista C, D'Agruma L, Bertoldo F, Florio C, Minisola S, Hendy GN et al. Blood ionized calcium is associated with clustered polymorphisms in the carboxylterminal tail of the calcium-sensing receptor. Journal of Clinical Endocrinology and Metabolism 200489 5634-5638. (doi:10.1210/jc.2004-0129)

24 Christensen SE, Nissen PH, Vestergaard P, Heickendorff L, Rejnmark L, Brixen K \& Mosekilde L. Skeletal consequences of familial hypocalciuric hypercalcemia vs primary hyperparathyroidism. Clinical Endocrinology 200971 798-807. (doi:10.1111/j.1365-2265.2009.03557.x)

25 Isaksen T, Nielsen CS, Christensen SE, Nissen PH, Heickendorff L \& Mosekilde L. Forearm bone mineral density in familial hypocalciuric hypercalcemia and primary hyperparathyroidism: a comparative study. Calcified Tissue International 201189 285-294. (doi:10.1007/s00223011-9517-x)

26 Brown EM. Role of the calcium-sensing receptor in extracellular calcium homeostasis. Best Practice \& Research. Clinical Endocrinology \& Metabolism 201327 333-343. (doi:10.1016/j.beem.2013.02.006)

27 Marie PJ. The calcium-sensing receptor in bone cells: a potential therapeutic target in osteoporosis. Bone 201046 571-576. (doi:10.1016/j.bone.2009.07.082)

28 Eller-Vainicher C, Chiodini I, Battista C, Viti R, Mascia ML, Massironi S, Peracchi M, D'Agruma L, Minisola S, Corbetta S et al. Sporadic and
MEN1-related primary hyperparathyroidism: differences in clinical expression and severity. Journal of Bone and Mineral Research 200924 1404-1410. (doi:10.1359/jbmr.090304)

29 Carnevale V, Pipino M, Antonacci M, Checchia C, D'Alessandro V, Errico M, Greco A \& Varriale A. Prevalence of hypercalcemia in hospitalised patients: effects of "correction" for serum albumin values. Journal of Endocrinological Investigation 200528 15-27. (doi:10.1007/ BF03347215)

30 Genant HK, Wu CY, van Knijk C \& Nevitt M. Vertebral fracture assessment using a semi-quantitative technique. Journal of Bone and Mineral Research 19938 1137-1148. (doi:10.1002/jbmr. 5650080915)

31 Eller-Vainicher C, Cairoli E, Zhukouskaya VV, Morelli V, Palmieri S, Scillitani A, Beck-Peccoz P \& Chiodini I. Prevalence of subclinical contributors to low bone mineral density and/or fragility fracture. European Journal of Endocrinology 2013169 225-237. (doi:10.1530/ EJE-13-0102)

32 Naylor K \& Eastell R. Bone turnover markers: use in osteoporosis. Nature Reviews. Rheumatology 20128 379-389. (doi:10.1038/nrrheum.2012.86)

33 Gupta M, Cheung C-L, Hsu Y-H, Demissie S, Cupples LA, Kiel DP \& Karasik D. Identification of homogeneous genetic architecture of multiple genetically correlated traits by block clustering of genomewide associations. Journal of Bone and Mineral Research 201126 1261-1271. (doi:10.1002/jbmr.333)

Received 28 April 2014

Revised version received 11 June 2014

Accepted 25 June 2014 